\title{
Research on Teaching Reform of Chinese Courses in Local Colleges Against the Background of Online Courses
}

\author{
Jiahui Jiang ${ }^{1, *}$ \\ ${ }^{1}$ School of Literature and Journalism, Sichuan University, Chengdu, Sichuan 610064, China \\ *Corresponding author. Email: 490951007@qq.com
}

\begin{abstract}
The development of online courses has brought challenges to Chinese teaching in local colleges, and has had a certain impact on the traditional teaching mode, teacher's role awareness, and student participation. These challenges warn that local colleges and universities must increase the reform of Chinese language courses, use online courses to improve the construction of Chinese language courses, encourage teachers to change their ideas and reform the curriculum teaching system, strengthen students' practical training and improve their ability to use Chinese.
\end{abstract}

Keywords: online courses, local colleges, Chinese course teaching

\section{INTRODUCTION}

The development of modern educational technology has given birth to online open courses, which overturn the traditional teaching model that relies on face-to-face teaching in the classroom. It combines the advantages of TV teaching, network teaching and classroom teaching, so that students can register the online courses by using the internet and computers or smart phones. Since the first year of MOOC in 2012, online open courses have gradually entered universities and large-scale network platforms, giving college students and the other people the same learning opportunities. These courses are becoming an important way for people to learn high-quality courses. The rapid development of online open courses has brought about the craze for MOOCs and set off a revolution in the education sector. This wave has prompted schools at all levels and types around the world to rapidly carry out teaching reforms that adapt to them.

\section{THE CURRENT STATUS OF ONLINE} COURSES

Although it has only been a few years since the birth of online open courses, it has produced a huge response in the global education community. Not only are the universities and institutions participating in the development increasing, the number and types of courses offered and the number of students have also increased significantly.

\section{A. Online courses are booming}

In 2012, several universities in the United States launched online open course platforms represented by Coursera, Uadacity, and Edx. Everyone can register for courses provided by the free learning platform. The emergence of these platforms has made the best use of high-quality teaching resources and provided more people with opportunities to learn university courses, which has aroused great repercussions in the education sector. Subsequently, countries have joined or followed suit. Canada, Britain, Australia, France, China, Japan and other countries have also launched their own online open courses. In just a few years, both large-scale open MOOCs and small-scale restrictive private classes have made great progress.

In 2013, Tsinghua University signed the American education online platform Edx, and then Fudan University and Shanghai Jiaotong University signed the American course platform Coursera. Joining also started independent construction. At present, China's more mature online course platforms include Tsinghua University's "Xuetang Online", Shanghai Jiaotong University's "Good University Online", and the "Eastern and Western Universities Curriculum Sharing Alliance" led by Chongqing University, including Peking University, Fudan University, Sichuan University, Lanzhou University, Haerbin Institute of Technology, more 
than 40 universities. In addition, Netease, Baidu, Sina and other large websites have also launched open courses or cloud classrooms. Such as Baidu Chuanke, Netease Cloud Classroom, Sina Open Class, etc., as well as the China University MOOC jointly launched by Netease and Higher Education Press. It presents a vigorous development situation of independent construction of universities, joint construction, website joint university construction, and coexistence of online courses and mixed classrooms.

With the rapid development of MOOCs and various online courses, the Ministry of Education issued the "Opinions on Strengthening the Application and Management of Online Open Curriculum Construction in Colleges and Universities" in 2015 [1], pointing out that universities should earnestly undertake the construction of online open courses. The main responsibility of application and management is to construct and use online open courses as an important measure to promote education and teaching reform, and take online open courses as an important supplement to classroom teaching. Since then, on the basis of more than 3,000 national quality courses selected during the "Eleventh FiveYear Plan" period, the Ministry of Education has jointly established a domestic online course resource sharing platform "iCourse" website with the Higher Education Society. The website mainly displays "Chinese University Video Open Courses", "Chinese University Resource Sharing Courses" and MOOC. These courses provide high-quality course resources from various universities in China for teachers and students of universities and the other. So far, the construction of online open courses in China has begun to take shape and is developing vigorously.

\section{B. Advantages and disadvantages of online courses}

Online open courses have the incomparable advantages of traditional classroom teaching, allowing high-quality teaching resources to be used to the greatest extent. Any student who is willing to learn an online course can register for free. Moreover, each video generally teaches a knowledge point, and the duration is about 10 minutes, which is convenient for students to use various spare time for fragmented learning. The video can also be played repeatedly, taking into account the learning progress of students of different levels, so that students who have not fully understood have the opportunity to listen to the class repeatedly. This type of teaching solves the regret that traditional classroom teaching can only be listened to once at a fixed time and place, and students can also get answers in the discussion area when they encounter problems. The discussion process can not only enable the students to learn from each other, but also prompt the teachers to discover the problems in the teaching in time, so that the teaching can be mutually beneficial. At the same time, it is also convenient for teachers to count the learning time of students, and to understand the learning situation of students in time.

The disadvantage is that the course completion rate is low and there are few professional core courses. For online courses, although there are many registrants, there are few who insist on completing the study and obtaining a certificate. This is the case around the world. "A survey in the United States showed that among the 1 million people who participated in 16 courses on the Coursera platform from June 2012 to June 2013, the average course completion rate was only $4 \%$. There is a similar survey in China in November 2013. A survey conducted by Guokr MOOC Academy on more than 6000 MOOC learners shows that the completion rate of MOOC courses is only 6\%." [2] Due to the particularity of online learning, teachers cannot provide for students who do not complete their studies on time and take exams. Constraint, it is even impossible to determine whether it is the registrant who participated in the study and examination. At the same time, although the online courses currently developed involve many disciplines, they are mainly public courses and not many professional courses. Even if some courses are nominally professional courses, the actual content is reduced in depth and difficulty with a certain degree of professionalism. Popular courses. "China's original online courses are mainly general, life, hobby, and certification training. Higher education level professional online courses account for a small proportion." [3] Currently, core Chinese courses such as modern Chinese and ancient Chinese There are very few corresponding platforms that offer online courses in Chinese, Introduction to Linguistics. In September 2017, Nanjing University first launched the MOOC of Modern Chinese, which made up for this gap. Too little proportion of professional core courses will undoubtedly limit the coverage of online courses and reduce the influence of courses.

In addition, each online course has an open course selection period. After the course selection period, you need to wait until the next class start time to register for learning. After the course, you can no longer ask the teacher or communicate with the students at the same time. It cannot be as stable as classroom teaching. The relationship between teachers and students and classmates is not convenient for long-term communication. Moreover, the face-to-face guidance and seminars required by highly professional courses are not available in online courses. Furthermore, the 
instructor is not always online, and students' questions can only be answered after the teacher is online, unlike classroom teaching that can be answered on the spot.

\section{Challenges OF ONLINE COURSES TO CHINESE TEACHING IN LOCAL UNIVERSITIES}

Facing the rapid changes in educational methods and the requirements of the Ministry of Education, it is impossible for local colleges and universities to continue to follow the traditional teaching model. They must face up to opportunities and challenges and make their own choices. They can use existing curriculum resources to reform the traditional teaching model, or strive to build online courses with their own characteristics. The teaching of Chinese courses inherently has many problems that urgently need to be reformed, such as dull teaching mode, single assessment method, and outdated teaching content. The popularity of online courses has brought new challenges to the reform of Chinese courses.

\section{A. Challenges to traditional teaching models}

The development wave of online courses not only poses challenges to the teaching management of universities, but also poses severe challenges to professional construction and curriculum construction. For many years, the teaching of Chinese courses has tended to emphasize theory teaching and neglect course practice, and emphasize test scores and neglect ability training. Faced with the impact of online courses, these problems have had a more prominent negative impact on Chinese teaching. Old-fashioned teaching content, rigid teaching mode, and single assessment method have seriously affected the teaching effect of Chinese courses. In the Internet age, great changes have taken place in the way students acquire knowledge, the entire teaching environment, and society's requirements for talents. These changes require curriculum teaching models to be updated accordingly, highlighting interest, practicality, and novelty. If the traditional teaching model is not changed, the phenomenon of absenteeism or using mobile phones in class will get worse.

\section{B. Challenges to teachers themselves}

In the Internet age, teachers are no longer the authoritative holders of knowledge, and the function of teachers to preach and teach karma to solve puzzles still exists, but the method has changed. Part of the knowledge a teacher possesses is obtained by inheriting the learning of the predecessors, and part is the teacher's own experience and innovation. The former can be obtained by students through literature reading or online courses, while the latter needs to be obtained by the teacher himself. Online courses have put forward new requirements for teachers' teaching level and role awareness. "University teachers have become service providers of knowledge to students, a supervisor, not a manager of teaching." [4] What teachers should do is identifying complicated knowledge and information, and providing students with reading and study guidance, so that students know what to choose in the ocean of knowledge. This urges teachers themselves to constantly update their knowledge structure, keep up with the changes of the times and academic frontiers, make full use of the characteristics of the Internet age, choose the best teaching methods, and be inherited and innovative teachers.

Online courses also challenge teachers' awareness, level and ability to deeply integrate information technology and professional knowledge. "Teachers must achieve selftranscendence according to the requirements of MOOC, so that they not only possess traditional subject expertise, but also master modern information technologies such as information technology, network technology, virtual reality technology, data mining technology, cloud information, etc., and promote themselves from academic teachers to academics transformation of compound teachers with equal emphasis on technology." [5] At the same time, online courses undoubtedly increase the workload of teachers. Teachers must spend more time preparing and uploading course videos, and make time for online tutoring. This is also a great test for teachers' energy and dedication.

\section{Challenges to students' learning styles}

Online courses pose a challenge to students' learning participation. The traditional teaching mode of Chinese courses is that teachers take the initiative to teach, students listen passively, and the teacher is the leader of the classroom. Students take notes in class and make surprise reviews before the exam. Students who get high marks may not have mastered the essence of the course. Serious students can extend reading and complete related homework as required, while non-serious students just review before the exam. Regardless of the level of participation and the actual level, the final pass will get credits. When the employer selects talents, it is also difficult to judge the actual Chinese ability of the students based on the results. Online courses require students to participate in the entire learning process. First watch the video to learn the lecture content, participate in the discussion and leave the post as proof, then complete each chapter homework or unit test, and finally participate in the final assessment of the course. Missing any teaching link will lose the corresponding score of 
that link. This kind of teaching design urges students to fully participate in the course learning, otherwise it will affect their grades and lose their qualifications for credits. It is precisely because students have to put in more energy and time to ensure the effect of learning, and some students eventually did not stick to the end, forming a situation of more registration and fewer passes.

\section{THE REFORM PATH OF CHINESE COURSES IN LOCAL UNIVERSITIES}

\section{A. Taking advantage of online courses to improve the construction of course groups}

The construction of online open courses is costly and requires hundreds of thousands. The state's funding input is mainly concentrated in 985 colleges and 211 colleges and universities, and famous teachers are gathered in the abovementioned colleges and universities, local colleges lack both funds and famous teachers. "The popularity of MOOCs has fully demonstrated the style of well-known universities at home and abroad. However, for local universities, MOOCs may bring more impact. MOOCs may mean the loss of students in the classroom and may even threaten the school's survive." [2] Local colleges and universities can only turn crises into opportunities, learn from the advantages of online courses of prestigious schools, do not repeat construction, and use their general course resources to mainly build professional courses. Currently, online courses are mainly public courses, and there are not many professional courses. As far as Chinese courses are concerned, just take the MOOC of Chinese universities as an example. Of the 1,235 courses currently offered by 137 universities, only 4 are Chinese courses, namely "Modern Chinese", "Dialects and Chinese Culture", "Ancient Chinese Characters", and "Fun Chinese". Among them, "Modern Chinese" was first launched by Nanjing University in September 2017. Among them, "Fun Chinese" is only 32 hours, which is offered as a general course, not a professional course. Moreover, among the Chinese course groups, highly specialized courses such as Modern Chinese, Ancient Chinese, phonology, exegetics, and introduction to linguistics require face-to-face guidance, and cannot rely solely on online courses, and require simultaneous online and offline construction. In recent years, local colleges and universities have been actively constructing highquality courses and open video courses. They have concentrated their superior resources. On the basis of the original course construction, with modern Chinese and Ancient Chinese as pilots, the construction of Chinese courses has been gradually improved and completed. Local colleges and universities have built small-scale professional core online courses. Even if the credits of some general courses in other universities are recognized, local colleges and universities need to test the actual learning effect of students in an appropriate way, so that teachers of this school can properly intervene in the students' online learning process and avoid opportunistic situations.

\section{B. Reforming the traditional teaching model}

Online courses and traditional courses have their own advantages and disadvantages. The reform of Chinese teaching in local colleges can only develop by combining the advantages of both parties and avoiding the original shortcomings. Specifically, we can start from the aspects of changing the teacher's role consciousness, reforming the curriculum teaching system, and highlighting students' practical training. Focusing on the ability to use Chinese, it's needed to change the traditional teaching model centered on "textbooks, classrooms, and teachers" and replace it with an applied teaching model that is "studentcentered, practice-based, and ability-enhancing as the goal".

The first is to change concepts, grasp the role of teachers in the new era, and be a guider, urger and resolver of student learning. "University teachers cannot rely solely on the traditional teachercentered teaching model, and cannot rely solely on exams to measure student learning or check and balance student performance. They must completely change the teaching philosophy based on teaching, reposition the role of teachers, and update teaching concepts. The research on the educational and teaching concepts of the university, combined with the learning characteristics of students, explores different online and offline teaching modes such as flipped classrooms and blended teaching to achieve diversified teaching." [6] In the Internet age, students have diverse and timely means of acquiring knowledge, and teachers do not have to replay the old tune of knowledge that students can acquire on their own in the classroom. It is necessary to adjust the teaching objectives, teaching methods and teaching content at the right time to be an innovative teacher that meets the needs of the times and society. If teachers in local colleges and universities have no sense of crisis and insist on teaching according to the old model, they will eventually face the situation of being eliminated by the times and students.

The second is the reform of the existing teaching system, including talent training goals, curriculum integration, and assessment management. The core goal of Chinese courses is to improve students' language literacy, enhance their language ability, and meet the special needs of students at different levels to ensure that all students have the corresponding professional 
Chinese ability. In terms of curriculum integration, existing mature online courses, such as "Charming Chinese" and "Palaeographology", can be used directly, and students can register for learning by themselves, and the school will recognize credits based on the certificate of passing the course. Teachers can also register for learning at the same time to understand the main problems of students. Other courses can learn from the characteristics of MOOC's ability to watch repeatedly, and use LAN and micro-teaching to record the content of teachers' lectures and provide them to students in need for repeated learning, so as to solve the drawback of classroom teaching that can only be listened to once. In the assessment mode, the final course scores of students are not determined by the scores of the examination papers, but only as a reference. According to the characteristics of the courses and the needs of social employment, the ability to use Chinese is the focus of the assessment, and the experience of the occupational Chinese proficiency test and the Putonghua proficiency test is used for reference, and diversified assessment methods and performance evaluation methods are adopted.

The third is to pay attention to the effect of students' learning and highlight their participation. By reforming the traditional assessment and evaluation mechanism, the effect of student participation is affirmed. The first is to allow students to actively manage their own learning behaviors and learning effects, strengthen teacherstudent interaction and student-student interaction, and understand and test students' learning situation and mastery at any time through practical training. The second is to encourage students to participate in various language competitions. If a student participates in a competition that demonstrates language ability and wins, in addition to recording the corresponding credits, it can also be part of the relevant course scores. The assessment of all Chinese courses is based on application ability. Each course has its own emphasis. It jointly examines the students' oral and written language ability, and reflects their comprehensive quality through the overall results of the course group. This is also conducive to cultivating and selecting applied talents suitable for local economic and cultural construction.

\section{Highlighting the characteristics of local and application}

Local colleges and universities have limited funds and famous teachers, so there is no need to repeat the construction of mature online courses that have been established by other colleges and universities, and they can be used directly. Based on locality, highlighting the application-oriented approach is the focus of the reform of Chinese courses in local colleges and universities. "Local colleges and universities can adopt the mode of cultivating talents in cooperation with other colleges and universities. For the non-advantageous and non-characteristic majors of local colleges, they can use the higher quality MOOC resources provided by the cooperative universities. Students learn MOOCs independently, and teachers of local colleges will provide classroom guidance and Q\&A; for local college's superior majors and specialties with strong characteristics, they can concentrate their own teachers to build MOOCs, or form teaching teams with famous teachers and experts from partner universities to build MOOCs." [7] Local universities can start from two aspects to build applied online courses with local characteristics.

The one is to give full consideration to the particularity of local demand for talents, and to reform the curriculum and to construct scientific Chinese language ability training goals, so that the trained talents can quickly integrate into the local area and become the talents of employers. For Chinese language courses, what local universities need to do is to equip students with different Chinese abilities, mainly the ability to use Chinese and the ability to study Chinese. According to the specific circumstances of the student source, training goals are set at different levels, highlighting personalized learning. For most students, the core is to cultivate their ability to use Chinese, including Chinese teaching ability and Chinese writing ability; for a small number of students who need further studies, they will deepen their theoretical foundation and knowledge accumulation in the form of elective courses in the upper grades, in order to cultivate their Chinese research ability; for a few of students with poor Chinese proficiency, we will organize Chinese improvement classes for them to gradually improve their Chinese proficiency to prevent them from being unable to successfully complete other courses due to their poor Chinese proficiency. At the same time, students are also required to pay attention to the cultivation of Chinese dialect ability and prepare for future service to the place and smooth communication with the local people.

The second is to combine language teaching with the spread of local culture. For local college students, on the one hand, they should have a relatively high standard of using Chinese and dialects; on the other hand, they should have the ability to inherit and disseminate language and culture. First, it's necessary to cultivate students' awareness of serving the local economic and cultural construction. In the selection of teaching content, appropriate examples of language and culture in the region are added, practical training is emphasized in the course teaching process, and 
Chinese teaching is combined with dialect investigation, culture and folklore investigation and research. It's needed to group to strengthen practical training, so that students can understand, master, disseminate, and inherit the local language and culture in the investigation. Eventually, the students will become applied talents who are proficient in standard Chinese and can work with the local dialect, serving the local education, economic and cultural construction.

\section{CONCLUSION}

Facing the vigorous development of online courses, local colleges and universities can only actively respond, make use of high-quality course resources, and build online courses with their own characteristics in order to benefit their survival and development. Although the popularity of online open courses has brought great challenges to the traditional courses of local colleges and universities, the challenges are also opportunities. It not only provides local colleges with opportunities to learn from high-quality curriculum resources, but also prompts local colleges to further strengthen curriculum construction and improve education ways to cultivate high-quality applied talents.

\section{References}

[1] "Opinions of the Ministry of Education on Strengthening the Construction, Application and Management of Online Open Courses in Colleges and Universities" (Jiaogao [2015] No. 3)" [EB /OL]. [2016-09-01]. http://www.moe.edu.cn/publicfiles/business/htmlfiles/moe/ s7056/201504/186490.html

[2] Jiao Jian, Wei Yun. Challenges and opportunities for talent training in local universities under the background of MOOC [J]. Science Education Journal, 2016, (8): 7-11.

[3] Liu Hua. Integration of online courses into the university curriculum teaching system: obstacles and breakthroughs [J]. Higher Education Research, 2016, (5): 68-72.

[4] Kang Xiao-hong. The role change and challenge of college teachers under the upsurge of MOOC [J]. China Adult Education, 2016, (14): 125-127.

[5] Kang An-feng. On the role positioning and reshaping of MOOC teachers [J]. Higher Education Exploration, 2016, (12): 94-99

[6] Zhou Jun-hua. Research on the Development Strategy of University Teachers under the Wave of "MO Class" [J]. Journal of University of Shanghai for Science and Technology (Social Science Edition), 2015, (3): 270-273.

[7] Deng Qiong-fen. Analysis of teaching reform in local colleges and universities in the era of MOOC [J]. Journal of Jiaying University (Philosophy and Social Sciences), 2016, (1): 80-83 